\title{
DROUGHT DETECTION BY APPLICATION OF REMOTE SENSING TECHNOLOGY AND VEGETATION PHENOLOGY
}

\author{
Yannawut Uttaruk', Teerawong Laosuwan ${ }^{1,2}$ \\ 1 Faculty of Science, Mahasarakham University, Katarawichai, Mahasarakham, 44150, Thailand \\ 2 Space Technology and Geoinformatics Research Unit, Faculty of Science, Mahasarakham University, \\ Mahasarakham, 44150 Thailand \\ Corresponding author's e-mail: teerawong@msu.ac.th
}

Received: 2017.08 .03 Accepted: 2017.09 .05 Published: 2017.11.01

\begin{abstract}
Drought is a natural phenomenon as it often occurs in the area of Yasothon province, northeastern of Thailand. It causes effects on vegetation condition in the area. Drought information might be useful for local government to prepare for prevention and mitigation plan in the future. For this reason, the primary objective of the research was to conduct the examination of this province to find severe drought years. Firstly, the researcher needed to find Normalized Differences Vegetation Index (NDVI) and Vegetation Condition Index (VCI) by analyzing monthly Landsat data acquired at different periods of time from January to December 2014, 2015, and 2016, covering $4,096 \mathrm{~km}^{2}$. Then, the researcher needed to find relationship between VCI and monthly rainfall represented in term of space and time. As results, VCI and its relationship with monthly rainfall were congruent. VCI showed that the drought area was $33.87 \%$ or $1,387.32 \mathrm{~km}^{2}$ of studied area in $2014,16.24 \%$ or $665.19 \mathrm{~km}^{2}$ of studied area in 2015 and $27.95 \%$ or $1,144.83 \mathrm{~km}^{2}$ of studied area in 2016 . Therefore, the most and the least severe drought years were 2014, 2016, and 2015 respectively.
\end{abstract}

Keywords: drought detection, remote sensing, vegetation phenology

\section{INTRODUCTION}

Drought, one of natural disasters, results from delayed seasonal rainfall which leads to water shortage. This situation has a great influence on people, lifestyle and world economic. Drought in Thailand is also a concerned issue since it has an effect on the economy, social life and environment. Global climate change causes in temperature rising. During the last century $(1901-2000)$, world's average temperature has increased by 0.6 degree Celsius, which also increases the precipitation rate for $5-10 \%$ at the equatorial and the north hemisphere regions while the precipitation rate in south hemisphere regions decreases greater than 3\% (Gomasathit et al., 2015). In Thailand, drought is not a new issue, but it recurs every year, especially in the north-eastern region.
The major cause of drought is low precipitation level, which often recurs every cold season until hot season (Laosuwan et al., 2016). Water deficiency affects to vegetation phenology which will be, in turn, indicate the drought severity level (Wattanakij and Mongkolsawat, 2008; Laosuwan et al., 2016). Remote sensing technology is modern and up-to-date technology that is able to apply for many situations especially natural disaster prediction such as drought, flooding, soil erosion and etc. (Laosuwan and Rotjanakusol, 2013; Laosuwan and Uttaruk, 2014; Yannawut and Teerawong, 2017; Teerawong and Yannawut, 2017; Dušan et al., 2017).

The application of remote sensing technology can enable to detect the climate in drought area, which is manifested by changing in vegetation phenology (Xiaoyang et al., 2003; Toshihiro et al., 
2005). For example, Landsat satellite's data are gathered in order to follow changes in vegetation phenology (Fisher et al., 2006; Hui et al., 2015). The reason is that Landsat satellite can continuously record the repetitive data, follow an area in real-time and contain multi-temporal data. These advantages greatly implement the evaluation of some changing on the earth's surface. After satellite's data is operated by image processing and mathematical equation, the data will obviously manifest the details of the study. For instance, the Normalized Difference Vegetation Index (NDVI) is calculated by the differences between wavelength of red and near infrared (Geerken et al., 2005; Per et al., 2015; Mushtaq and Asima, 2016; Uttaruk and Laosuwan, 2016). The NDVI calculation results will indicate the vegetation phenology dynamic in each climate area. This study aims to examine the drought area in Yasothon province, which is located in the north-eastern region of Thailand, by using a combination of Landsat's satellite data, Normalized Difference Vegetation Index (NDVI) data and Vegetation Condition Index (VCI) data. The study was performed for 3 years in $2014-2016$.

\section{RESEARCH DATA AND METHODS}

\section{Research data}

Landsat 8 satellite's data: Landsat 8 is the US observation satellite, which is developed under the cooperation of NASA and USGS. Landsat 8 has been launched on February 11, 2013. It has 16 days repeat cycle for a round of the earth coverage and provides $185 \mathrm{~km}$ in scene size. There are 2 image capture modes including Operational Land Imager (OLI) and Thermal Infrared Sensor (TIRS). Landsat 8 contains 11 bands (Table 1)

Table 1. Landsat 8 specifications

\begin{tabular}{|c|l|c|}
\hline Bands & \multicolumn{1}{|l|}{ Wavelength (micrometers) } & Resolution (meters) \\
\hline 1 & $0.43-0.45$ (Coastal aerosol) & $30 \mathrm{~m}$ \\
\hline 2 & $0.45-0.51$ (Blue) & $30 \mathrm{~m}$ \\
\hline 3 & $0.53-0.59$ (Green) & $30 \mathrm{~m}$ \\
\hline 4 & $0.64-0.67$ (Red) & $30 \mathrm{~m}$ \\
\hline 5 & $0.85-0.88$ (Near IR) & $30 \mathrm{~m}$ \\
\hline 6 & $1.57-1.65$ (SWIR-1) & $30 \mathrm{~m}$ \\
\hline 7 & $2.11-2.35$ (SWIR-2) & $30 \mathrm{~m}$ \\
\hline 8 & $0.50-0.68$ (Panchromatic) & $15 \mathrm{~m}$ \\
\hline 9 & $1.36-1.38$ (Cirrus) & $30 \mathrm{~m}$ \\
\hline 10 & $10.60-11.19$ (Thermal IR 1) & $100 \mathrm{~m}$ \\
\hline 11 & $11.50-12.51$ (Thermal IR2) & $100 \mathrm{~m}$ \\
\hline
\end{tabular}

with spatial resolution (pixel) of 30 meters (visible, NIR, SWIR); 100 meters (thermal); and 15 meters (panchromatic). This study employs the Landsat 8's monthly data during $2014-2016$ at path 127 row 49.

Precipitation data: The average monthly precipitation data is obtained from rain gauge station in Yasothon province under the operation of the Meteorological Department of Thailand.

\section{METHODS}

\section{NDVI analysis}

This method calculates the differences between electromagnetic reflection in red and near infrared band. NDVI ranges from -1 to +1 . The negative (-) value indicates the wetland area, while the value close to zero indicates less vegetation area. In the dense vegetation area, NDVI value is close to +1 . Therefore, NDVI is widely used to analyze and to predict the vegetation phenology dynamic, which is resulted from its nearby environment. The NDVI can be calculated using Equation 1 (Tucker, 1979; Uttaruk and Laosuwan, 2016).

$$
N D V I=\frac{N I R-R E D}{N I R+R E D}
$$

where: $N I R=$ Near Infrared Band

$R E D=$ Red band

\section{$\mathrm{VCl}$ analysis}

The maximum vegetation will be manifested in a year that has suitable climate condition. It is because the climate will trigger the potential utilization of natural resources. On the other hand, the minimum vegetation will be in a year that has the least suitable climate e.g. drought, which directly inhibit vegetation growth. Therefore, the NDVI value, which is calculated by using data of the different climate from several years, can be used as a criterion to quantify vegetation phenology. However, the researchers have been developed the novel NDVI using the splitting of climate signal from ecological signal as well as make used of the maximal and minimal NDVI value. The novel NDVI will be concerned as VCI value (Kogan, 1997; Kogan, 2001; Domenikiotis et al., 2004; Quiring, S. M., and S. Ganesh, 2010; Wenzhe et al., 2016). VCI value varies in the range of $0-100$, which corresponds to the maximal and 
minimal vegetation phenology dynamic. VCI calculation and classification are shown in Equation 2 and Table 2, respectively.

$$
V C I=\frac{N D V I-N D V I_{\min }}{N D V I_{\max }-N D V I_{\min }} \times 100
$$

where: $N D V I_{\max }=$ Maximum NDVI at study time of each pixel

$N D V I_{\min }=$ Minimum NDVI at study time of each pixel.

\section{Multi-temporal analysis}

The multi-temporal analysis provides the overall satellite's data of this 3-year study (2014-2016). In this study, VCI result will be analyzed together with the precipitation data from rain gauge station in Yasothon province under the operation of the Meteorological department.

\section{Statistical analysis}

In this study, VCI result and precipitation data in 2014, 2015 and 2016 will be analyzed using linear regression analysis.

Table 2. VCI classification

\begin{tabular}{|c|l|}
\hline $\mathrm{VCl}$ (value) & \multicolumn{1}{|c|}{$\mathrm{VCl}$ (vegetation phenology) } \\
\hline $00.00-20.00$ & Very low vegetation (very high drought) \\
\hline $21.00-40.00$ & Low vegetation (high drought) \\
\hline $41.00-60.00$ & $\begin{array}{l}\text { Moderate vegetation (moderate } \\
\text { drought) }\end{array}$ \\
\hline $61.00-80.00$ & High vegetation (low drought) \\
\hline $81.00-100.00$ & Very high vegetation (very low drought) \\
\hline
\end{tabular}

\section{RESULTS}

\section{NDVI analysis results}

The monthly NDVI result in 2014 represents the vegetation phenology in the range of -1 to 1 , which follows the theory. The average value can indicate a vegetation phenology or a drought in each season. The maximal average, 0.69 , indicates the nearly end of rainy season in October, whereas the minimal average, 0.11 , indicates the end of cold season in February.

The monthly NDVI result in 2015 represents the vegetation phenology in the range of -1 to 1 , which follows the theory. The maximal average, 0.67 , indicates the end of rainy season in October, whereas the minimal average, 0.14 , indicates the hot season in June.

The monthly NDVI result in 2016 represents the vegetation phenology in the range of -1 to 1 , which follows the theory. The maximal average, 0.49 , indicates the rainy season in July, whereas the minimal average, 0.15 , indicates the cold season in September.

\section{$\mathrm{VCl}$ analysis results}

In this study, VCI analysis is shown as 3 months' value corresponding to season including summer season (January 17 - May 16), rainy season (May 17 - October 16) and cold season (October 17 - February 16). The average 3-years VCI analysis (2014-2016) is shown in Figure 1. The line indicates the variation of VCI value in each season.

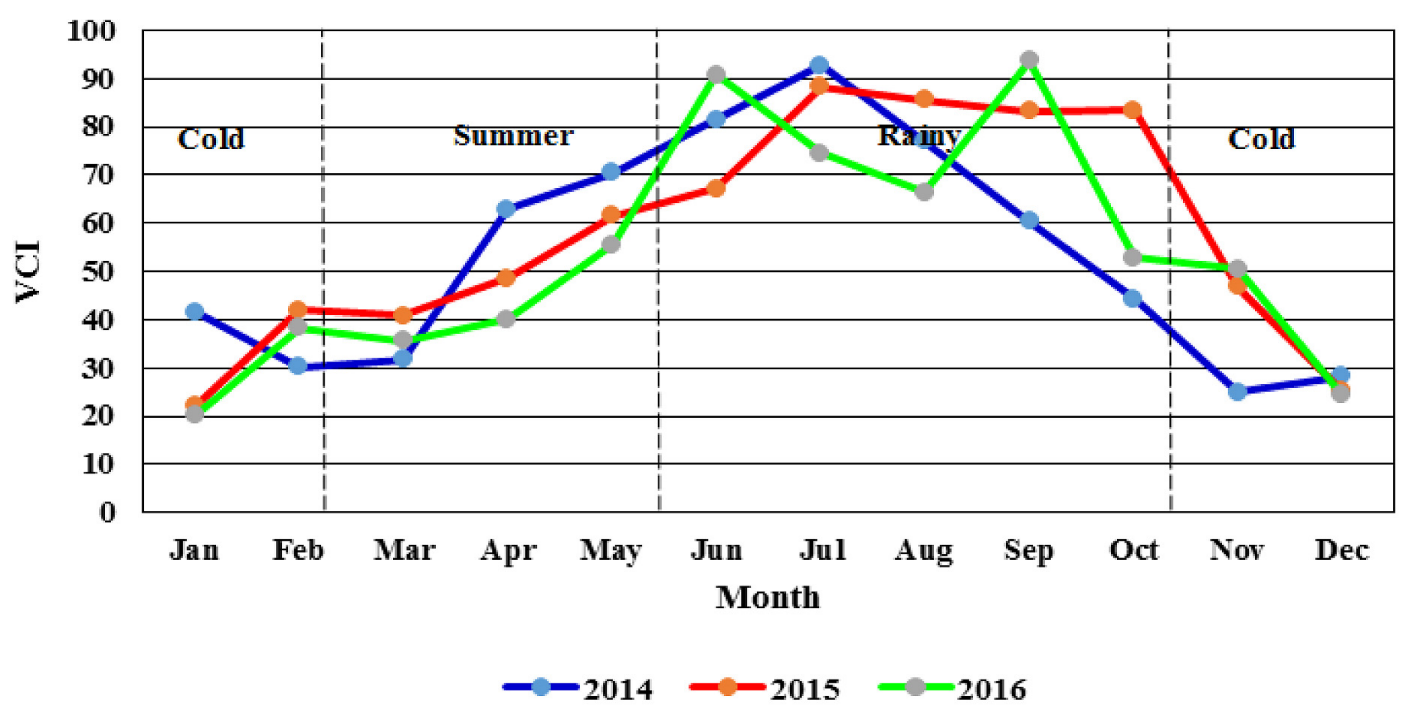

Figure 1. VCI analysis 
In Figure 1, the monthly VCI analysis result in 2014 shows that the differences in vegetation phenology is in $0-100$, which follow the theory. The average value can indicate a vegetation phenology or a drought in each season. The monthly VCI analysis results in 2014 reveal that the maximal average is 92.73 on July, which is rainy season, while the minimal average is 28.29 on December, which is cold season.

The monthly VCI analysis result in 2015 shows that the differences in vegetation phenology is in $0-100$, which follow the theory. The average value can indicate a vegetation phenology or a drought in each season. The monthly VCI analysis results in 2015 reveal that the maximal average is 88.3 on August, which is rainy season, while the minimal average is 22.09 on January, which is cold season.

The monthly VCI analysis result in 2016 shows that the differences in vegetation phenology is in $0-100$, which follow the theory. The average value can indicate a vegetation phenology or a drought in each season. The monthly VCI analysis results in 2016 reveal that the maximal average is 93.64 on September, which is rainy season, while the minimal average is 20.11 on January, which is cold season.

\section{Multi - temporal analysis results}

According to VCI and precipitation data analysis results, the changing in multi-temporal of VCI and monthly precipitation level are corresponded to each other as shown in Figure 2, and the conclusions are;
In 2014, the minimal changing in precipitation level is during January - February, then gradually increases until it reaches the maximal value on July and drops down to the minimal value in November.

In 2015 , the minimal changing in precipitation level is during January - February, then gradually increases until it reaches the maximal value in July and drops down to the minimal value in December.

In 2016, the minimal changing in precipitation level is during January - February, then gradually increases until it reaches the maximal value in September and drops down to the minimal value in December.

\section{Statistical analysis results}

The statistical analysis between VCI (independent variable) and precipitation level (dependent variable) in 2014, 2015 and 2016 reveals that the VCI changing corresponds to the amount of precipitation. The analysis results are shown in Figure 3-5.

According to the statistical analysis of VCI and the amount of precipitation in 2014 (Figure 3 ), the regression line is $y=5.4034 x-163.78$, and the coefficient of determination $\left(\mathrm{R}^{2}\right)$ is 0.7835 . The coefficient of determination $\left(\mathrm{R}^{2}\right)$ close to 1 indicates high relationship.

According to the statistical analysis of VCI and the amount of precipitation in 2015 (Figure 4), the regression line is $y=3.1829 x-87.246$, and the coefficient of determination $\left(\mathrm{R}^{2}\right)$ is 0.8497 .
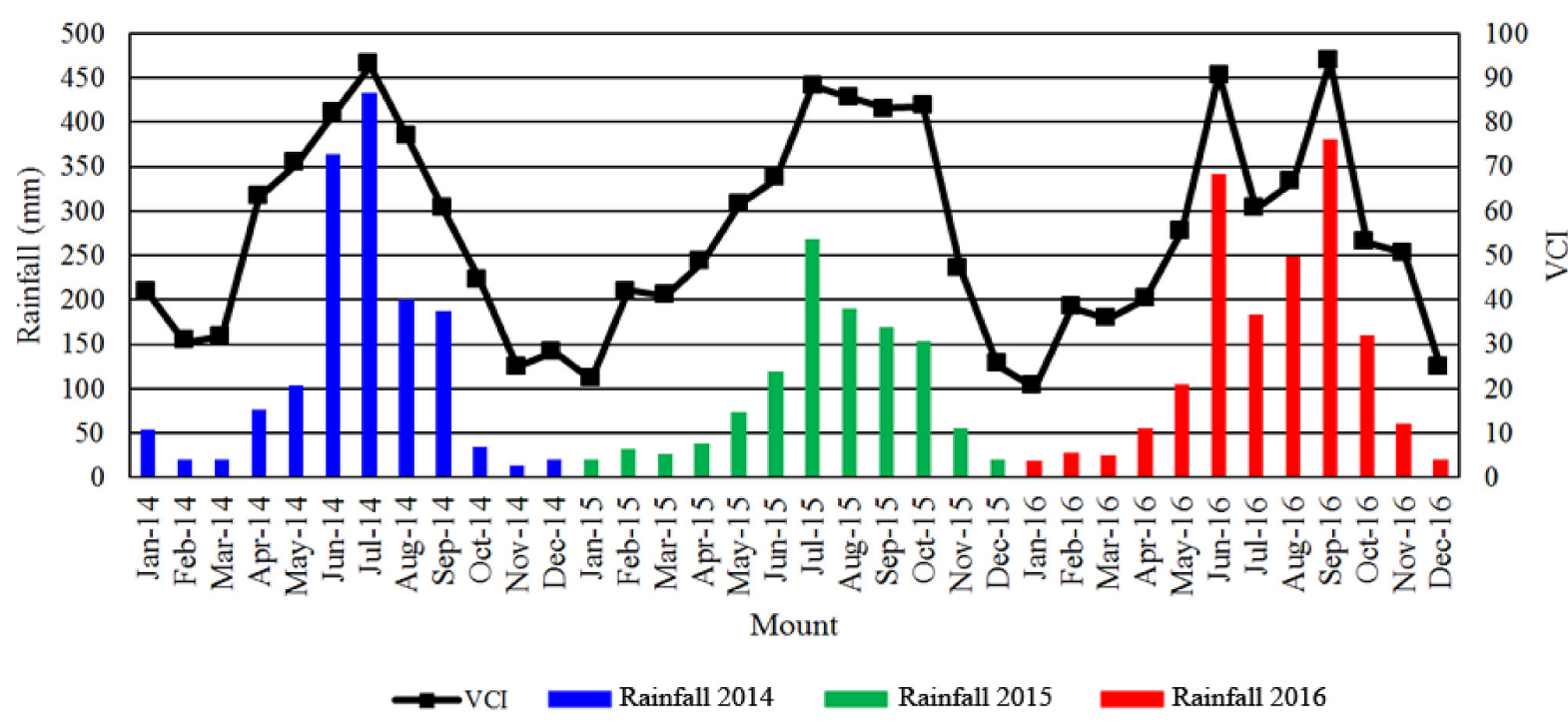

Figure 2. Multi-temporal analysis results 


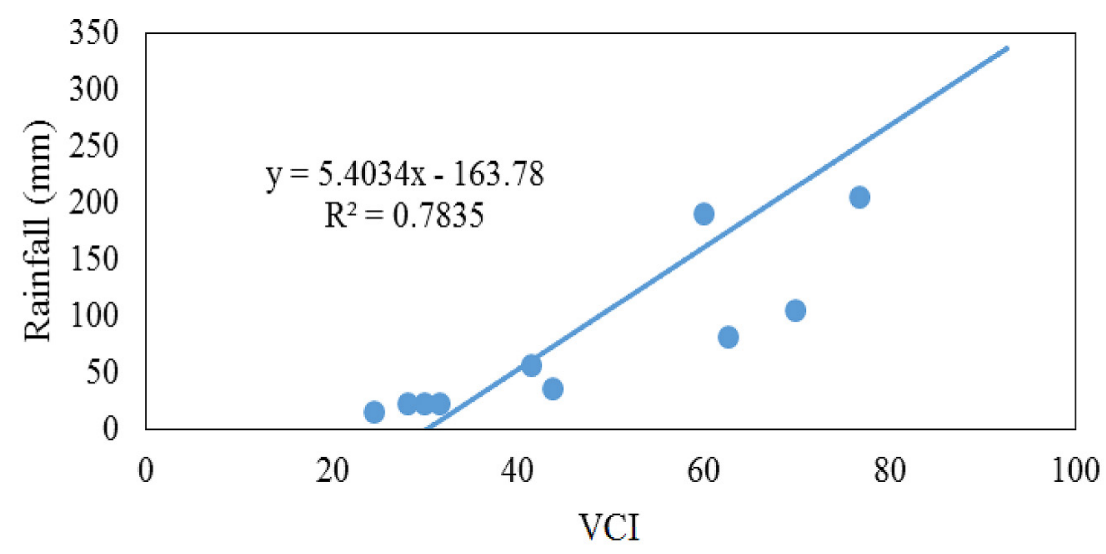

Figure 3. Statistical analysis in 2014

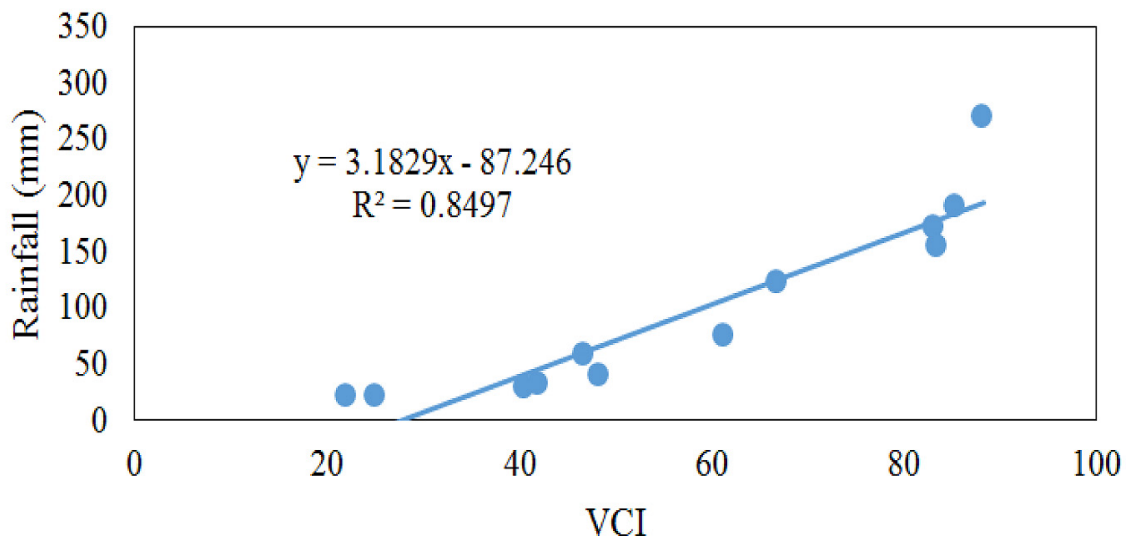

Figure 4. Statistical analysis in 2015

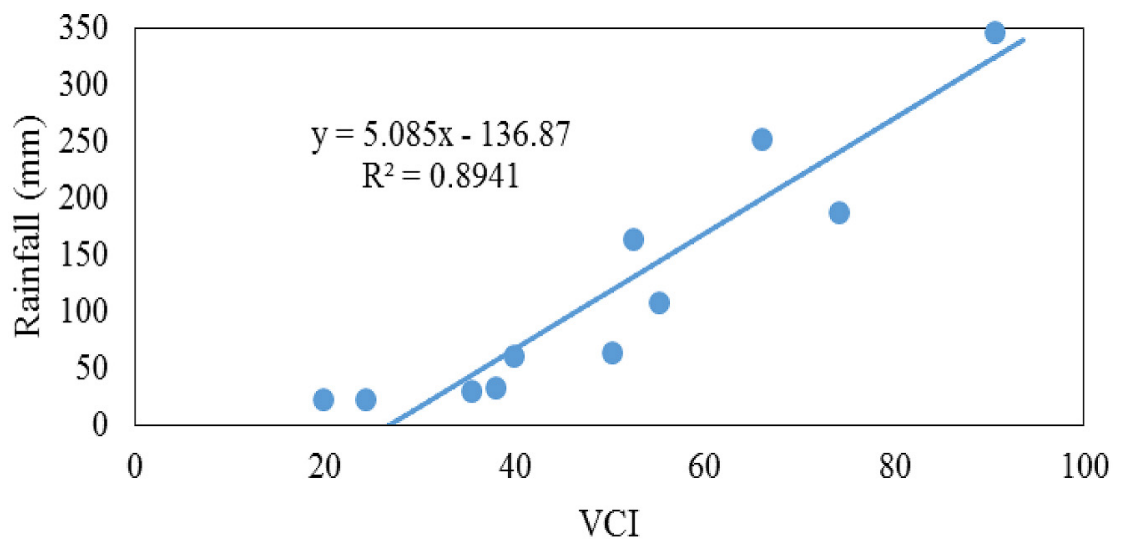

Figure 5. Statistical analysis in 2016

The coefficient of determination $\left(\mathrm{R}^{2}\right)$ close to 1 indicates high relationship.

According to the statistical analysis of VCI and the amount of precipitation in 2016 (Figure 5), the regression line is $y=5.085 x-136.87$, and the coefficient of determination $\left(\mathrm{R}^{2}\right)$ is 0.8941 . The coefficient of determination $\left(\mathrm{R}^{2}\right)$ close to 1 indicates high relationship.

\section{CONCLUSSIONS}

According to 3-years VCI analysis, the most intense drought is manifested in 2014, which has $33.87 \%$ or $1,387.32 \mathrm{~km}^{2}$. Next, in 2016 , the drought is $27.95 \%$ or $1,144.83 \mathrm{~km}^{2}$. The least intense drought was found in 2015 , which has $16.24 \%$ or $665.19 \mathrm{~km}^{2}$. Moreover, the results of 
multi-temporal changing analysis between VCI and monthly precipitation analysis reveal that the amount of precipitation is in concordance to the study's period in all 3 years, which is shown in a standard curve in Figure 2. The more the VCI value is, the higher the amount of precipitation retrieves. On the contrary, the lesser the VCI value is, the lower the amount of precipitation retrieves. However, the changing in VCI value is slightly slower than the changing in the precipitation since plants tend to grow under sufficient water supply condition. In addition, according to statistical analysis of 3 years VCI value (independent variable) and monthly precipitation level (dependent variable), the coefficient of determination $\left(\mathrm{R}^{2}\right)$ is $0.7835,0.8597$ and 0.8941 in 2014,2015 and 2016, respectively. The coefficient of determination $\left(\mathrm{R}^{2}\right)$ of every year is close to 1 , which indicates high relationship. The results of this study provide a criterion to reasonably determine the drought area in Yasothon province. Moreover, the evaluation of drought area will be trustworthy and relatively fast. Other departments can obtain and apply this method to evaluate and predict drought in other regions in Thailand.

\section{Acknowledgements}

This research was financially supported by Faculty of Science, Mahasarakham University.

\section{REFERENCES}

1. Domenikiotis, C., Spiliotopoulos, M., Tsiros, E., and Dalezios, N. R. (2004). Early Cotton Yield Assessment by The Use Of The NOAA/AVHRR Derived Drought Vegetation Condition Index In Greece. Int. J. Remote Sens., 25, pp. 2807-2819.

2. Dušan Húska, Luboš Jurík, Lucia Tátošová, Karol Šinka, Johana Jakabovičová. (2017). Cultural Landscape, Floods and Remote Sensing. Journal of Ecological Engineering. 18 (3), pp. 31-36.

3. Fisher, J. I., Mustard, J. F., \& Vadeboncoeur, M. A. (2006). Green leaf phenology at Landsat resolution: Scaling from the field to the satellite. Remote Sensing of Environment, 100, pp. 265-279.

4. Geerken, R., Batikha, N., Celis, D., Depauw, E. (2005). Differentiation of rangeland vegetation and assessment of its status: field investigations and MODIS and SPOT VEGETATION data analyses, International Journal of Remote Sensing, 26:20, pp. 4499- 4526.

5. Gitay H., Suárez A., Watson R.T., and Dokken
D.J., Eds., (2002). Climate Change and Biodiversity, IPCC Technical Paper V, IPCC, Geneva, 85 p,

6. Gomasathit, T., Laosuwan, T., Sangpradit, S., and Rotjanakusol, T., (2015). Assessment of Drought Risk Area in Thung Kula Rong Hai using Geographic Information System and Analytical Hierarchy Process. International Journal of Geoinformatics, 11 (2), pp. 21-27.

7. Hui Fan, Xiaohua Fu, Zheng Zhang and Qiong Wu. (2015). Phenology-Based Vegetation Index Differencing for Mapping of Rubber Plantations Using Landsat OLI Data. Remote Sensing. 7, pp. 6041-6058

8. Kogan, F.N. (1997). Global drought watch from space. Bull. Am. Meteorol. Soc. 78, pp. 621-636.

9. Kogan, F. N., (2001). Operational space technology for global Vegetation Assessment. Bull. Amer. Meteor. Soc., 82(9), pp. 1949-1964.

10. Laosuwan T., and Rotjanakusol T., (2013). The Observation and Monitoring of Water Situation by Using Remote Sensing Technology and GIS, J. Sci. Technol. MSU., 32(2), pp. 246 -256

11. Laosuwan T., and Uttaruk P., (2014). Estimating Tree Biomass via Remote Sensing, MSAVI 2, and Fractional Cover Model, IETE Tech.Rev., 31(5), pp. 362-68.

12. Laosuwan, T., Sangpradit, S., Gomasathit, T., and Rotjanakusol, T., (2016). Application of Remote Sensing Technology for Drought Monitoring in Mahasarakham Province, Thailand. International Journal of Geoinformatics, 12 (3), pp. 17-25.

13. Mushtaq Ahmad Ganie and Asima Nusrath. (2016). Determining the Vegetation Indices (NDVI) from Landsat 8 Satellite Data. International Journal of Advanced Research, 4(8), pp. 1459-1463.

14. Per Skougaard Kaspersen, Rasmus Fensholt, and Martin Drews. (2015). Using Landsat Vegetation Indices to Estimate Impervious Surface Fractions for European Cities. Remote Sens. 7, pp. 8224-8249.

15. Quiring, S. M., and S. Ganesh. (2010). Evaluating the utility of the Vegetation Condition Index (VCI) for monitoring meteorological drought in Texas, Agric. For. Meteorol., 150(3), pp. 330-339.

16. Teerawong Laosuwan, Yannawut Uttaruk. (2017). Application of Remote Sensing for Temperature Monitoring: The Technique for Land Surface Temperature Analysis. Journal of Ecological Engineering. 18 (3), pp. 53-60.

17. Toshihiro Sakamoto, Masayuki Yokozawa, Hitoshi Toritani, Michio Shibayama, Naoki Ishitsuka, Hiroyuki Ohno.(2005). A crop phenology detection method using time-series MODIS data. Remote Sensing of Environment, 96 (3),pp. 366-374.

18. Tucker, C. (1979). Red and photographic infrared 
linear combinations for monitoring vegetation. Remote Sensing of Environment, 8, pp. 127 - 150.

19. Uttaruk Y., Laosuwan T., (2016). Remote sensing based vegetation indices for estimating above ground carbon sequestration in orchards. Agriculture and Forestry, 62 (4). pp 193-201

20. Wattanakij N., Mongkolsawat C., (2008). Drought Detection in Northeast Thailand using Standardized Vegetation Index of Multi-Temporal Satellite Data," In: Proc. 4th Environment Naresuan Conference, Naresuan Univeristy, Thailand, pp. 206-215.

21. Wenzhe Jiao, Lifu Zhang, Qing Chang, Dongjie Fu, Yi Cen and Qingxi Tong. (2016). Evaluating an Enhanced Vegetation Condition Index (VCI) Based on VIUPD for Drought Monitoring in the Continental United States. Remote Sens., 8(3), pp. 2-21.

22. Xiaoyang Zhang, MarkA. Friedl, Crystal B. Schaaf, Alan H. Strahler, John C.F. Hodges, Feng Gao, Bradley C. Reed, Alfredo Huete. (2003). Monitoring vegetation phenology using MODIS. Remote Sensing of Environment, 84 (3), pp. 471-475.

23. Yannawut Uttaruk, Teerawong Laosuwan. 2017. Carbon Sequestration Assessment of the Orchards using Satellite Data. Journal of Ecological Engineering. 18 (1), pp. 11-17. 